\title{
Erratum: A commognitive perspective on Grade 8 and Grade 9 learner thinking about linear equations
}

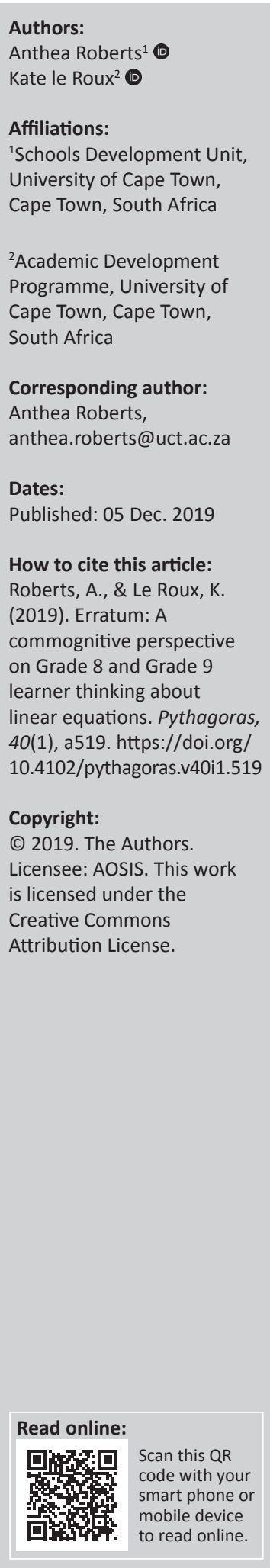

\section{Authors:}

Anthea Roberts ${ }^{1}$

Kate le Roux ${ }^{2}$

University of Cape Town,

Cape Town, South Africa

${ }^{2}$ Academic Development Programme, University of

Cape Town, Cape Town

Anthea Roberts,

Dates:

Published: 05 Dec. 2019

Roberts, A., \& Le Roux, K.

Erratum:

on Grade 8 and Grade 9

learner thinking about

linear equations. Pythagoras,

40(1), a519. https://doi.org/

Copyright:

(C) 2019. The Authors

Licensee: AOSIS. This work

is licensed under the

ution License.
In the version of this article published earlier, the date of publication reflected the incorrect year. The publication date, under the heading 'Dates', should have been 28 March 2019 instead of 28 March 2018.

This correction does not alter the study's findings of significance or overall interpretation of the study results. The publisher sincerely apologises for any inconvenience caused. 


\section{A commognitive perspective on Grade 8 and Grade 9 learner thinking about linear equations}

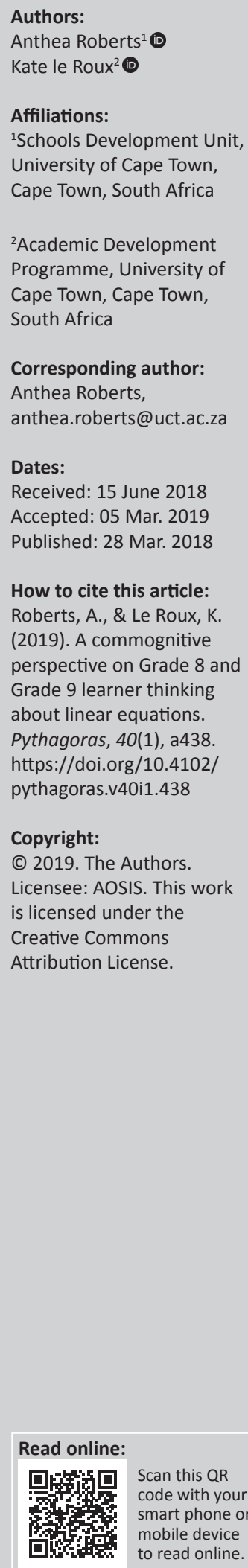

Concerns have been expressed that although learners may solve linear equations correctly they cannot draw on mathematically valid resources to explain their solutions or use their strategies in unfamiliar situations.

This article provides a detailed qualitative analysis of the thinking of 15 Grade 8 and Grade 9 learners as they talk about their solutions to linear equations in interviews. The article stems from a study that describes whether learners use mathematically endorsable narratives to explain and justify their solutions. Sfard's theory of commognition is used to develop a framework for analysis of their discourse.

The findings show that all learners use ritualised rather than explorative discourse, characterised by applying strict rules to operations with disobjectified entities. The only mathematical objects they produce endorsed narratives about are positive integers. Thus they do not meet the relevant curriculum requirements. Nevertheless, the analytic tools - adapted from Sfard specifically for the study of linear equations - give a particularly nuanced account of differences in the learners' ritualised discourse. For example, some learners used endorsed narratives about negative integers, algebraic terms and the structure of an equation when prompted by the interviewer.

There is not sufficient evidence to suggest that any learners are in transition to explorative discourse. However, the article shows that learner discourse is a rich resource for teachers to understand the extent to which learners are thinking exploratively, and offers suggestions for how their thinking can be shifted. This is an opportunity for teacher professional development and further research.

Keywords: school mathematics; discourse; algebra; linear equations; commognition.

\section{Introduction}

This article is located in the enduring and stubborn problem of poor mathematics performance among the majority of school learners in South Africa (Adler \& Pillay, 2017; Graven, 2014; Spaull, 2013).

Mathematics education research has, necessarily, focused on different aspects of this complex problem, for example wider socio-economic factors affecting performance (e.g. Setati, 2008; Taylor, 2009), school and classroom management (e.g. Fleisch, 2008; Taylor, 2009), teacher practice and professional development (e.g. Adler, 2011; Gardee \& Brodie, 2015; Venkat \& Adler, 2012), and learner thinking (e.g. Brodie, 2010; Gcasamba, 2014; Pournara, Hodgen, Sanders, \& Adler, 2016). This article focuses on learner thinking in the context of solving linear equations in Grade 8 and Grade 9.

Linear equations as a topic is productive for exploring learner thinking in these grades as learners transition from arithmetic to algebraic thinking. At this juncture, learners are expected to make a shift from seeing the equal sign as signifying an operation, to seeing this symbol as having relational significance and to using the notion of equivalence. In the South African school curriculum the topic is located in the content area 'Patterns, Functions and Algebra' (Department of Basic Education [DBE], 2011). The curriculum document describes the expected trajectory for learners' conceptual understanding of functions and algebra between Grade 7 and Grade 9 as a transition from 'a view of Mathematics as memorised facts and separate topics to seeing Mathematics as interrelated concepts and ideas represented in a variety of equivalent forms' (DBE, 2011, p. 21). The 'concepts and skills' for solving linear equations include using additive and multiplicative inverses, and 'substitution in equations to generate tables of ordered pairs' (DBE, 2011, p. 91). 
The study on which this article is based emerged from the practice of the first author who, in her experience in teacher professional development, found that neither she nor teachers could explain learners' incorrect solutions to linear equations. In addition, the marks assigned in conventional written assessments suggested that some learners could produce the correct answers to familiar-looking linear equations, yet interviews with learners, conducted to inform the design of a professional development course for teachers, provided a more complex assessment: when learners were required to explain their strategies it emerged that they were not using mathematically valid resources to solve these equations, and could not apply their strategies in unfamiliar situations. The most common procedure observed in these interviews involved shifting entities across the equal sign. There was some evidence of applying additive and multiplicative operations, but virtually no evidence that teachers encouraged learners to use relational equivalence as a resource for solving linear equations.

A review of the literature - presented in detail in the next section - suggests that the observation of learners' strategies in this context is not idiosyncratic. Research has pointed to the prevalence of the 'change side-change sign' technique (Kieran, as cited by Hall, 2002, p. 12), and the erroneous application of the distributive property (Seng, 2010, p. 153). Indeed, this literature suggests that, across contexts, learners tend to manipulate symbols in an instrumental way without knowing the reason for the procedure, rather than demonstrating relational thinking (compare Skemp, 1976), by recognising, using and explaining connections between mathematical structures and demonstrating which manipulations are useful to perform for particular problems (Hoch \& Dreyfus, 2004; Linchevski \& Livneh, 1999; Mason, Stephens, \& Watson, 2009).

The question could be posed: If learners produce correct answers to problems, why does it matter that they achieved their solutions by merely following an instrumental rather than a relational approach? Mathematics education researchers recognise the central role of relational thinking in the transition from arithmetic to algebra. Mason et al. (2009) argue that, while learning manipulation is part of mathematical sense-making, purely instrumental thinking restricts a learner to the particular and hence to rote learning. Relational thinking, on the other hand, is essential for generalising and abstracting. Sfard (2008) - who uses concepts such as explorative and ritualised discourse to describe different forms of thinking - suggests that both the how of solving a problem, that is, the procedure, and the when and why of using the procedure are hallmarks of using mathematically valid resources to think about mathematical objects in a way that is individualised, independent, and flexible. Her concern is that the thinking of learners who can solve problems without the when and why can only be restricted and rigid. Learners thinking in this way can only reproduce what others say or do, and remains heavily reliant on the situation and available mediational means. Sfard further suggests that imitative, procedural manipulation is a part of learning school mathematics, but that if the teaching focuses only on such, learners will not have the opportunity to transition further to the valued relational thinking. Certainly, the description of the school curriculum in this introduction suggests that the relational thinking regarded as important in the literature, is valued.

This article proceeds from the argument that decisions about teaching linear equations that promote relational thinking require detailed understanding of learner thinking on this topic. Thus, the aim of this article is to provide a theoretically informed description of the how, why and when of learner thinking when solving linear equations. To achieve this, we adopt the theory of commognition (Sfard, 2008). We describe the discourse of learners who knew how to solve familiar linear equations to search for evidence - based on Sfard's conceptualisation of mathematical thinking - that they are using mathematically valid resources to think about linear equations. Firstly, we describe each learner's communication using Sfard's concepts of explorative and ritualised discourse. Explorative discourse is the most sophisticated form and is characterised by narratives about mathematical objects that are endorsable in terms of mathematical axioms, definitions, and theorems. Ritualised discourse on the other hand involves the learner following, or imitating, strict rules that are determined by an authority. Secondly, for those learners whose discourse is classified as ritualistic, we delve deeper to ask whether there are any differences in the talk, gestures and writing of these learners, and whether some of them might be in transition to explorative discourse. We use these detailed descriptions of learner discourse about linear equations to make some tentative recommendations on how teachers could use the curriculum topics to support students in the transition from ritualised to explorative discourse.

\section{Literature review}

Most studies of learner thinking in the transition from arithmetic to algebra and more specifically about linear equations have drawn on cognitive theories of learning that can be located within an 'acquisitionist' paradigm of learning (Sfard, 2015, p. 130). Researchers have used theoretical concepts such as structure sense and relational versus instrumental thinking to characterise learner thinking. Defining structure sense as the ability to 'recognize mutual connections between structures, ... and recognize which manipulations it is useful to perform' (Hoch \& Dreyfus, 2004, p. 50), Hoch and Dreyfus (2006) found that the majority of Grade 10 learners in their study did not use structure sense as a resource when solving algebraic problems. Those that used structure sense made fewer errors, but there was no correlation between learners' structure sense and their manipulation skills. The latter finding suggests that learners might know how to solve problems but not the why and when aspects. Indeed, Linchevski and Livneh (1999) argued that not having a sense of the structure of the number system underpinned an absence of - in Skemp's (1976) terms relational understanding in algebra, that is, not having the 
conceptual structure that allows for independent decisions when solving problems. Focusing on learner thinking about the equal sign, Alibali, Knuth, Hattikudur, McNeil and Stephens (2007), Asquith, Stephens, Knuth and Alibali (2007) and Essien and Setati (2006) identified an absence of relational understanding of the equal sign as impeding flexibility in the solving of algebraic equations. The studies reviewed here used the concepts of structure and of relational and instrumental thinking to characterise learner thinking in algebra. In particular, they associate the former with relationship-rich, flexible, independent, more accurate problem solving.

Some studies of learners' algebraic thinking from within the acquisitionist paradigm have focused on describing the detail of how learners solve problems. The detail of learner errors is commonly described using the notion of misconception, that is, the use of a concept that, 'although systematic and invariant across contexts, differs from the way this concept is used by experts' (Sfard, 2008, p. 16). Focusing on linear equations and algebraic expressions, Hall (2002) and Seng (2010) showed that learners across geographic and socio-economic contexts present the same misconceptions. As noted, errors included the 'change side-change sign' technique (Kieran, as cited by Hall, 2002, p. 12) and erroneous application of the distributive property (Seng, 2010). Focusing on the equation $4 m=2 m$, De Lima and Tall (2008) noted that learners shifted symbols in a manner they described as using the notion of human embodiment: symbols were picked up and moved around. The detail of learner thinking offered by the research reviewed here can inform the development of teaching strategies to counter them, although these strategies could favour an instrumental rather than structural orientation to the concept.

The studies of thinking about linear equations reviewed here have commonly focused on linear equations in various forms, such as $a x+b=c, a x+b=c x+d$ and $4 m=2 m$ (e.g. Barahmand \& Shahvarani, 2014; De Lima \& Tall, 2008; Filloy \& Rojano's, 1989; Herscovics \& Linchevski, 1994). There is general agreement that learners respond differently to equations where there is a variable on one side of the equation, as opposed to equations where the variable occurs on both sides. However, researchers differ in their characterisation of the form of the latter that marks the transition from arithmetic to algebra. This debate lends weight to the point made by Herscovics and Linchevski (1994) that a study aiming to describe what learners do when solving linear equations must include a variety of equation forms. The different forms identified in this research have informed the methodological design of our research in this article.

The studies located within the acquisitionist paradigm reviewed here contribute to the mathematics education community's understanding of learner thinking when solving linear equations, by characterising learner thinking as instrumental or relational, identifying the importance of relational thinking for mathematical participation, and describing some detail of how learners think about linear equations. They have also made contributions to the methodological aspects of investigating learner thinking when solving these equations.

Yet, despite this extensive body of research, there is still a need for nuanced descriptions, not only of the how of learner thinking, but also the when and why of their strategies that help us to understand how learners might transition from instrumental to relational thinking. Sfard (2008) argues that such descriptions require additional data, and the focus of this article is on the thinking of 15 learners who knew that they had solved an equation correctly, but had difficulty explaining why. Such descriptions also need 'penetrating theories' (Sfard, 2008, p. 22) and we use Sfard's theory of commognition, located in a 'participationist' view of learning (Sfard, 2015, p. 130), for a nuanced description of these learners' thinking.

Indeed, the usefulness of commognition to 'penetrate' the detail of mathematical thinking is suggested by the growing use of this theory (see Special Issues edited by Tabach \& Nachlieli, 2016; Sfard, 2012). Commognitive studies focusing on learner thinking have included the shift from arithmetic to algebra (Caspi \& Sfard, 2012), functions (Clark, 2014; Gcasamba, 2014; Nachlieli \& Tabach, 2012; Tabach \& Nachlieli, 2011) and geometry (Sinclair \& Moss, 2012). Our literature review did not reveal any commognitive studies focusing exclusively on learner thinking about linear equations.

A number of researchers have used commognition to study change in learner discourse over time (Heyd-Metzuyanim, 2015; Nachlieli \& Tabach, 2012). Given the scope of the master's thesis on which this article draws (Roberts, 2016), we report only on learner thinking at a particular moment in the learning process. Furthermore, Viirman (2011), Berger and Bowie (2012) and Bogdanova (2012) all used the theory of commognition to study the discourse of teachers or lecturers or to develop courses for teachers. The studies reviewed here suggest that the detailed understanding of learner thinking at a particular moment that this article offers could inform teacher professional development, with followup research to explore shifts in learner thinking over time.

Achieving our aim of presenting the empirical detail of the how, when and why of learner thinking about linear equations in this article requires an explanation of (1) the detail of the key inter-related concepts we use from Sfard, and (2) how we put these to work in a framework for analysing learner discourse specifically about linear equations. We explain this detail next.

\section{Theory Overview}

Sfard (2008) argues that mathematics is a discursive activity. Unlike the objects of many school subjects, mathematical objects - numbers, variables and functions are examples - are not accessible to our senses. 
Learners of mathematics therefore construct these abstract objects through their discourse and we speak of discursively constructed objects. Sfard (2008) describes mathematics as 'autopoietic' (p. 129) in the sense that it is 'a system that contains the objects of talk along with the talk itself'. She identifies this as the feature that makes mathematics difficult to learn: familiarity with 'what the discourse is all about' (p. 130) is needed for participation in the discourse, but paradoxically this familiarity only comes through participation. To describe a learner's discourse in Sfard's terms we use the following key concepts, which are described in the rest of this section: keywords, visual mediators, narratives and routines, as well as the mathematical objects that are referenced.

\section{Keywords, visual mediators and narratives}

In Sfard's (2008) terms keywords are words that signify numbers, variables and functions. Visual mediators are the visible objects that act to communicate relationships and operations with mathematical objects. In mathematics these are mostly in the form of symbolic artefacts such as numerals, tables, algebraic expressions, equations and graphs. These symbolic artefacts are created to communicate relationships and operations with mathematical objects. Keywords and visual mediators are used to produce narratives (Sfard, 2008). A narrative is any text, spoken or written, that is 'framed as a description of objects, of relations between objects, or processes with or by objects' (Sfard, 2008, p. 300). Endorsed mathematical narratives are those that the mathematical community accepts as valid; definitions, proofs and theorems are examples of endorsed narratives in scholarly mathematics. This characteristic of narratives is a feature that we exploit in this article in order to categorise learners' discourse: we consider whether learners use keywords and visual mediators to construct endorsable narratives pertaining to the solution of linear equations. We do this by constructing narratives based on what is perceptible in their discourse during interviews (Sfard, 2017).

\section{Routines}

Regularities in the use of keywords and visual mediators, and their use in narratives, are referred to as routines (Sfard, 2008, p. 138). A routine may be a procedure such as 'taking' a number across the equal sign, or a practice such as generalising, endorsing or rejecting a narrative. Routines are governed by rules, which may be at the level of object (about the behaviour of objects) or a metalevel rule (metarule) that defines the pattern of learner actions. For example, the 'change sides-change signs' metarule (Kieran, as cited by Hall, 2002, p. 12) informs the routine in which learners solve linear equations by reorganising the position of algebraic terms. Sfard (2008) argues that school mathematics is dominated by metarules that define the how, rather than the when or why. In this article we consider learners' use of and awareness of the latter when solving linear equations, so that we can describe their thinking using the concepts of explorative and ritualistic discourse.
Sfard (2008) identifies rituals and explorations as different types of routines. The notion of mathematical object is key to distinguishing between these two routines, and we turn to this next.

\section{Mathematical objects and realisation trees}

We adopt Sfard's (2008) particular use of the concept of mathematical object here, noting that the term is used in various - and in some cases contested - ways in mathematics and mathematics education. Not all the 'objects' in a learner's discourse are necessarily mathematical objects in Sfard's sense as described in this section. Thus in this article we reserve the use of 'object' for cases that meet her definition and refer to other 'objects' as entities.

Since from a commognitive perspective mathematical objects are discursively constructed, a key feature of Sfard's (2008) notion of a mathematical object is the relationship between signifier and realisation. Sfard suggests that, when solving a linear equation algebraically, a learner will proceed from signifiers in the form of symbols or words. Each signifier would have particular significance for the learner. That significance produces a response (written or spoken), which is the realisation. Therefore, a signifier mediates meaning between one entity and another. The chain of signifiers and their realisations is referred to as a branch, and the final realisation is the solution to the problem. Sfard calls this chain a realisation tree. A signifier could lead to different realisations for different people. For example, some learners could talk about the term ' $-3 x^{\prime}$ as a mathematical object and operate on it in a mathematically endorsed way, but for others ' $3 x^{\prime}$ and ' - ' could be separate visual mediators and would thus signify separate operations that would not be endorsable.

Relational thinking could produce more than one way to solve a problem and each method would produce a different branch on the realisation tree. Sfard (2017) uses these concepts to describe a mathematical object, that is, 'a mathematical signifier together with its realization tree' (p. 43). These concepts are illustrated in Figure 1, the realisation tree for the solution to the linear equation $2 x+7=13$.

The realisation tree for the solution to the linear equation $2 x+7=13$ in Figure 1 has four branches. For the algebraic branch on the far right, the linear equation $2 x+7=13$ is a signifier that leads to the realisation ' $2 x+7-7=13-7$ '. Thus, ' $2 x+7=13^{\prime}$ and ' $2 x+7-7=13-7$ ' are a signifier-realisation pair. A signifierrealisation pair is referred to as a node (Sfard, 2008, p. 165). The signifier-realisation pairs for this branch ultimately lead to the realisation that $x=3$. However, the same linear equation $2 x+7=13$ could also signify a realisation of the ordered pair $(3 ; 13)$ in a graph, table or flow diagram, shown in the remaining three branches of the realisation tree. In summary, the realisation tree is 'a hierarchically organized set of all the realisations of a given signifier', together with their realisations (Sfard, 2008, p. 301).

In deciding whether a learner's discourse about linear equations is objectified, that is, whether the learner is acting 


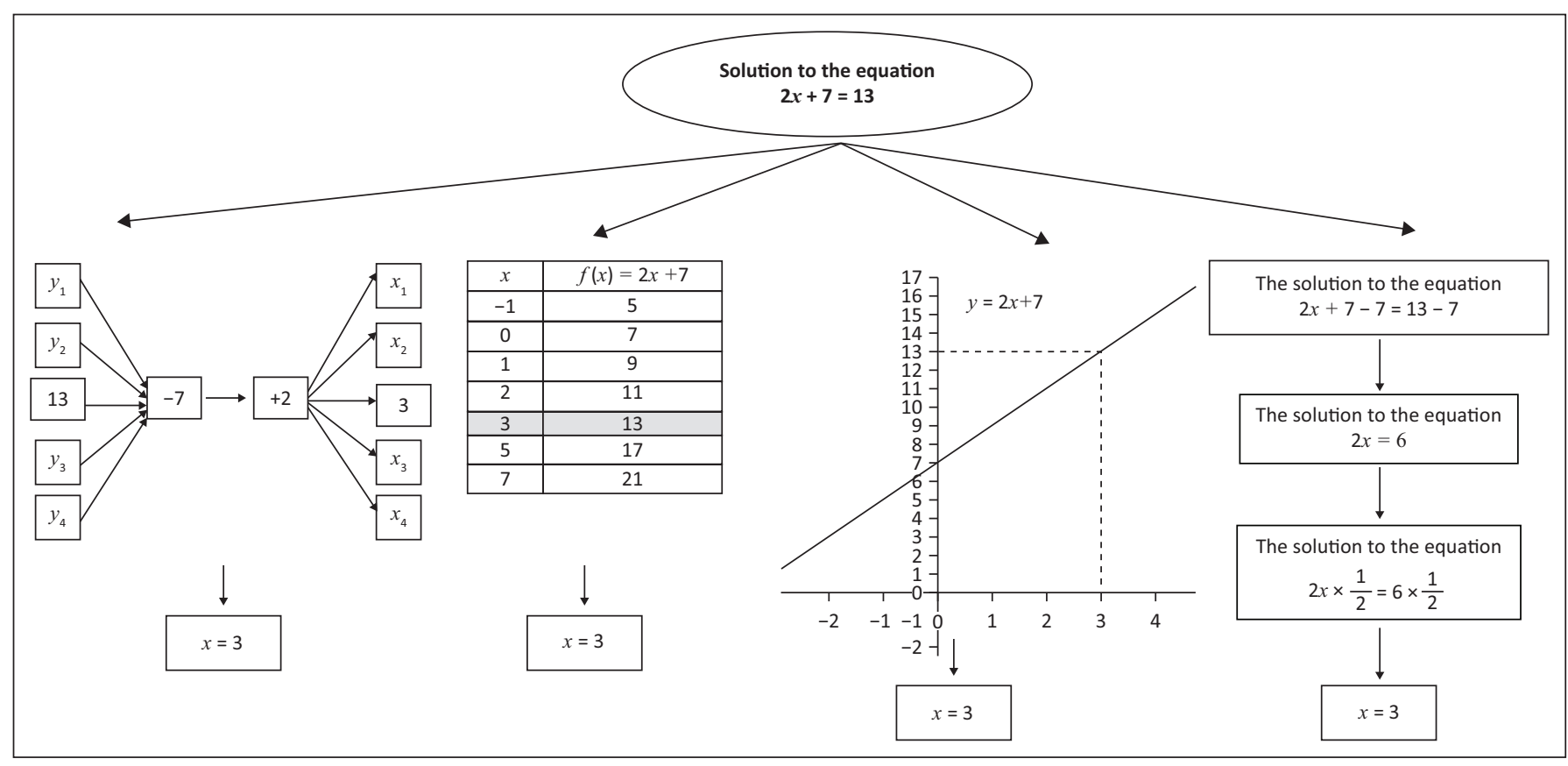

Source: Roberts, A. (2016). A study of Grade 8 and 9 learner thinking about linear equations, from a commognitive perspective. Unpublished master's thesis, University of Cape Town, Cape Town, South Africa (p. 36). Retrieved from https://open.uct.ac.za/handle/11427/20627

FIGURE 1: Realisation tree for the solution to the linear equation $2 x+7=13$.

TABLE 1: Signifier-realisation-narrative framework for the solution of $2 x+7=13$.

\begin{tabular}{|c|c|c|}
\hline Signifier & Realisation & Realising procedure \\
\hline $\begin{array}{l}\text { The solution to the } \\
\text { equation } 2 x+7=13\end{array}$ & $2 x+7-7=13-7$ & $\begin{array}{l}\text { Apply the additive inverse of }(+7) \text { to } \\
\text { both sides of the equation }\end{array}$ \\
\hline $\begin{array}{l}\text { The solution to the equation } \\
2 x+7-7=13-7\end{array}$ & $2 x=6$ & Add the like terms \\
\hline $\begin{array}{l}\text { The solution to the } \\
\text { equation } 2 x=6\end{array}$ & $\frac{2 x}{2}=\frac{6}{2}$ & $\begin{array}{l}\text { Apply the multiplicative inverse of } 2 \\
\text { to both sides of the equation }\end{array}$ \\
\hline $\begin{array}{l}\text { The solution to the } \\
\text { equation } \frac{2 x}{2}=\frac{6}{2}\end{array}$ & $x=3$ & \\
\hline
\end{tabular}

Source: Roberts, A. (2016). A study of Grade 8 and 9 learner thinking about linear equations, from a commognitive perspective. Unpublished master's thesis, University of Cape Town, from a commognitive perspective. Unpublished master's thesis, University of Cape Town,

with mathematical objects, we need to consider whether the story or narrative they construct to justify the relationship between a realisation and its original signifier is endorsed or not. In Table 1 , the first realisation ' $2 x+7-7=13-7$ ' is justified by applying the additive inverse of ' +7 ' to the expression on either side of the equal sign. This justification would be part of the narrative, which is endorsable because equivalence is preserved. Table 1 shows the endorsable iterative relationship between signifiers and realisations for the algebraic solution of the equation.

Sfard (2008, p. 166) notes that the realisation tree is a 'personal construct' because it represents the learner's discourse. By constructing realisation trees from each learner's talk about linear equations in interviews, we obtained visual representations of the discursive objects they constructed. This allowed us to identify whether their routines were ritualised or explorative, as explained next.

\section{Ritualised and explorative routines}

Explorations are the most sophisticated form of routine. Explorative discourse is characterised by narratives about mathematical objects that are endorsable in terms of mathematical axioms, definitions and theorems. In this article we look at the realisation tree analytically to determine whether the learner can use different ways to solve the equation. This is a hallmark of whether the learner is working with a mathematical object.

According to Sfard (2008), rituals are characterised by strict rules that are determined by an authority (the teacher or textbook). The discourse of rituals is limited to justifying how to do something, but not when to do so or why it works. Since mathematics is an autopoietic system, learners first imitate others, which makes rituals an acceptable interim phase in the learning process. This implies that their routines have been discursively mediated by the teacher. Ideally, the learner will gradually gain an understanding of the why and when, which is one of the markers of the transition from the discourse of rituals to explorative discourse. Explorative discourse for these learners may be described as the production of algorithmic realisations, where the narratives are intradiscursive - they are produced by manipulating existing narratives (Sfard, 2008). In explorative discourse, a learner's word and mediator use signify numbers, algebraic terms and functions as mathematical objects in their own right.

The trajectory whereby the learner shifts towards the attainment of explorative discourse is complex. Sfard (2008) identifies four phases in the use of words within the discourse; passive use, routine-driven use, phrase-driven use and objectified use (Sfard, 2008, p. 182). The passive use of mathematical terminology generally pertains to an initial encounter with a key word or phrase. Once the learner starts using the terminology in the context of mathematical routines, it becomes routine-driven. As the learner's confidence with the 
TABLE 2: Features of explorative and ritualised discourse about linear equations.

Explorative discourse

1. Degree of objectification of the learners' discourse

1.1 Word and mediator use signify numbers, algebraic terms and functions as mathematical objects in their own right:

1.1.1 Keyword use is object-driven.

1.1.2 Words and phrases in one line of an equation signify numbers and algebraic terms as mathematical objects.

1.1.3 Word and mediator use and narratives support horizontal equivalence between functions in one line of an equation.

1.1.4 Word and mediator use and narratives support vertical equivalence, that is, one equation is a signifier that realises equivalent narratives.

1.1.5 The equation signifies more than one realisation. Thus, learners can use more than one representation of function in their solution.

2. Extent to which the learners' narrative is endorsed

2.1.1 Narratives about the structure and properties of mathematical objects are endorsable.

2.1.2 Mathematically endorsed resources (i.e. mathematical objects and valid procedures) result in procedures that produce endorsed narratives.

2.1.3 Narratives about the rules of arithmetic when explaining procedures are endorsable.

3. Closing condition (goal)

3.1 The goal is to produce an endorsed narrative about mathematical objects.

4. For whom the routine is performed

4.1 Learner's discourse is internally persuasive, depends on self and mathematical properties.

5. By whom the routine is performed

5.1 Learner works independently.

6. Level of flexibility

6.1 Learner makes permissible variations to the solution procedure to suit the task.

7. Level of correctibility

7.1 Learner recognises unendorsed narratives and corrects them.

Source: Adapted from Sfard (2008). Thinking as communicating: Human development, the growth of discourses, and mathematizing. New York, NY: Cambridge University Press ( $\mathrm{p}$. 243)

terminology expands, it becomes phrase-driven and used as part of constant phrases. Ultimately the learner would use words as nouns, appropriately across contexts, and thus in an objectified way. A learner would be initiated to explorative discourse through others' - mainly teachers and textbooks objectified use of words and visual mediators.

Table 2 outlines the criteria for evaluating discourse and shows the distinguishing features of explorative and ritualised discourse, which we have adapted from Sfard (2008, p. 243) for the focus on linear equations.

\section{Methodology}

Studying learner thinking when solving linear equations from a commognitive perspective involves investigating learners' discourse about mathematical objects. The study of their verbal and non-verbal communication in interviews is thus productive for the purpose.

\section{Selection of learners}

The interviews used in this study were initially conducted by the first author in the development of a short course for teachers. Twenty-two Grade 8 and Grade 9 learners at two schools were selected to take part.

There were no specific criteria for the selection of the schools, other than that the short course was being developed for their teachers. Following Gripper (2011), they were selected on the basis of their marks for their written assessments, which suggested they knew how to solve familiar linear equations. It was thus possible to investigate the learners' sense of the when and why, characteristics of explorative discourse.
Ritualised discourse

1.2 Word and mediator use signify talk and action on entities:

1.2.1 Keyword use is routine-driven and phrase-driven.

1.2.2 Words and phrases in one line of an equation signify mediators and actions with mediators as entities. Reference to spatial arrangement of entities and sequence of actions.

1.2.3 Word and mediator use and narratives disrupt horizontal equivalence between functions in one line of an equation.

1.2.4 Word and mediator use and narratives disrupt vertical equivalence, that is, equations are not equivalent narratives.

1.2.5 The equation signifies only one realisation, the algebraic solution to the linear equation.

2.2.1 Narratives about entities and relations between entities are not endorsable.

2.2.2 Narratives about the procedure for solving linear equations (e.g. person, spatial arrangement or visual appearance) are not endorsable.

3.2 The goal is to complete a procedure that leads to the line $x=\ldots$

4.2 Learner's discourse depends on outside authority, spatial arrangement, or the appearance of entities.

5.2.1 Learner depends on scaffolding (e.g. interviewer or mediator as prompt). 5.2.2 Learner references others as a source.

6.2 Learner follows the procedure in a strictly defined and rigid way.

7.2 Learner does not recognise unendorsed narratives or correct them.

In order to understand the learners' interview responses in more detail, the research study that forms the basis of this article was conceptualised in order to investigate the learners' discourse in the interviews. Of the original 22 learners interviewed, 11 Grade 8 learners and 4 Grade 9 learners agreed to have their interviews analysed for the purposes of the research study.

\section{Ethical considerations}

Permission to conduct the interviews for the purposes of teacher professional development was covered under the Memorandum of Understanding between participating schools and the organisation providing the support. Ethical approval for the research study was given by the ethics review committee of the Faculty of Humanities at the university (reference EDNREC20180909). Written permission to use the interviews for research purposes (including the publication of findings) was obtained from learners, their parents, the principals of the two schools and the provincial education department. Consent forms focused on issues of informed consent, anonymity, confidentiality and recognisability, and harm.

\section{The interviews}

The linear equations used in the interviews (Table 3) were selected from formal written assessment tasks that the learners had completed for their teachers. By implication, we had no control over the actual equations presented in each task. We note that for Equation 2, the Grade 8 equation $' 2 x+8=-3 x-2$ ' contains more negative integers than the Grade 9 equation ' $6 x-12=2 x+4^{\prime}$. The curriculum prescribes that from Grade 7 learners solve problems involving addition 
TABLE 3: List of interview questions, with motivation.

\begin{tabular}{|c|c|c|c|}
\hline Description & Grade 8 task & Grade 9 task & Questions to learners \\
\hline $\begin{array}{l}\text { Equation } 1: a x+b=c \\
\text { Only one term contains the variable. }\end{array}$ & $2 x+7=13$ & $2 x+7=13$ & $\begin{array}{l}\text { a. Explain your solution. } \\
\text { b. Would the solution to } 13=2 x+7 \text { be the same? } \\
\text { c. What is the value of } x \text { in the equation } 2 x+7=6+7 \text { ? }\end{array}$ \\
\hline $\begin{array}{l}\text { Equation 2: } a x+b=c x+d \\
\text { The variable appears more than once. }\end{array}$ & $2 x+8=-3 x-2$ & $6 x-12=2 x+4$ & a. Explain your solution. \\
\hline $\begin{array}{l}\text { Equation 3: } a(x+b)=c(x+d) \\
\text { Inclusion of brackets; learners first have to } \\
\text { transform the equation to the form } a x+b=c x+d .\end{array}$ & $7(x-3)=7-2(3 x+1)$ & $2(4 x-5)-(3 x+6)=-2(x+3)$ & $\begin{array}{l}\text { a. Explain your solution. } \\
\text { b. If you substitute your solution for } x \text { in the original equation, will } \\
\text { you get the same value on the left-hand side and right-hand side? }\end{array}$ \\
\hline
\end{tabular}

and subtraction of integers, and recognise and use the commutative and associative properties of addition and multiplication for integers (DBE, 2011, p. 16).

For each set of questions in the assessment tasks set by the two teachers, the instruction was 'Solve the following equations'. At the start of the interview learners were asked to explain what they understood by this instruction, following which they were asked what an equation was and to explain the meaning of the equal sign. Some equations in the assessments were modified for further investigation of learners' level of exploratory discourse. These modifications, as well as a linear equation with no constant term, were based on forms of linear equations used in other research studies, for example with the variable appearing more than once (Filloy \& Rojano, 1989; Herscovics \& Linchevski, 1994) and equations with no constant term (Barahmand \& Shahvarani; 2014; De Lima \& Tall, 2008). Table 3 lists the equations and related questions used in the interviews.

During the interviews learners were encouraged to point at entities in the written solutions. They were asked to elaborate on their responses and, where necessary, were provided with prompts and scaffolding. For example, after explaining how they solved the equation $2 x+7=13$, learners were asked whether the equation $2 x+7=6+7$ was another representation of the same thing. The following excerpt illustrates how the interviewer used questioning to prompt a Grade 8 learner, Sheena (pseudonym), in different ways:

\begin{tabular}{|c|c|c|}
\hline Line 1 & Interviewer: & $\begin{array}{l}\text { Okay and without doing the next step } \\
\text { can you tell me what } 2 x \text { is equal to just } \\
\text { by looking at that? }\end{array}$ \\
\hline Line 2 & Sheena: & Yes. \\
\hline Line 3 & Interviewer: & What's it? \\
\hline Line 4 & Sheena: & $2 x$. \\
\hline Line 5 & Interviewer: & $2 x ?$ \\
\hline Line 6 & Sheena: & Oh, sorry it's 6. \\
\hline Line 7 & Interviewer: & Why's it $6 ?$ \\
\hline Line 8 & Sheena: & $\begin{array}{l}\text { Because } 2 \text { times } 3 \text { is } 6 \text { [points to the } 2 \text { and } \\
\text { the } x \text { of } 2 x \text { ] and } 6 \text { plus } 7 \text { is } 13 \text { [points to } 2 x \\
+7 \text { on left-hand side] and } 6 \text { plus } 7 \text { is } \\
\text { thirteen [points to } 6+7 \text { on right-hand side]. }\end{array}$ \\
\hline
\end{tabular}

The interviewer's prompt in Line 1 is a question aimed to encourage Sheena to use the concept of equivalence to solve the problem. This differs from the prompt in Line 5, where the interviewer revoices Sheena's response in question form,

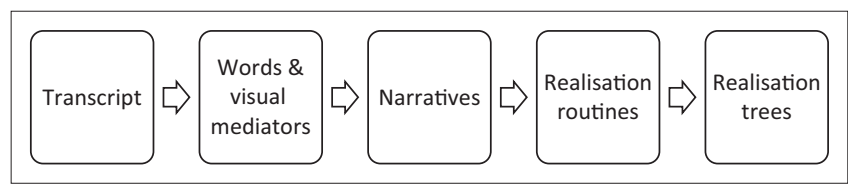

FIGURE 2: Steps in the Level 1 analysis from transcript to realisation.

to signal that she should rethink her response in Line 4 . The prompt in Line 7 asks Sheena to provide an explanation.

The interviews were audio- and video-recorded, with the video recorder focused on each learner's script, and related gestures and not their faces. The interview recordings were transcribed into Excel spreadsheets by the first author. What was said and done was 're-presented' (Setati, 2003, p. 294) in adjacent columns of the spreadsheet, to enable an analytic focus on a learner's word use and the visual mediators that accompanied this.

\section{Analysis process}

The analysis was organised into two levels. At Level 1 a learner's words and visual mediators were identified and used to reproduce the routines and narratives, and ultimately their realisation trees (with each recorded in a column of the spreadsheet). The data in these columns allowed us to perform the Level 2 analysis; it provided the evidence for us to classify a learner's discourse using the seven features of explorative versus ritualised discourse (Figure 1).

\section{Level 1 analysis: Operationalising the tools of the discourse}

Figure 2 illustrates the progression from transcript to realisation tree in the Level 1 analysis, as described in this section.

To briefly illustrate how we use Sfard's (2008) concepts to analyse the detail of a learner's discourse, we focus in this section on a short excerpt from the interview with, Sheena, based on her initial solution to the equation $2 x+8=-3 x-2$ (Extract 1). Sheena was awarded full marks for her written solutions to equations 1, 2 and 3 . We focus on the discourse of all 15 learners, including Sheena in the presentation of the findings:

$\begin{aligned} 2 x+8 & =-3 x-2 & & \text { Line 1 } \\ 2 x+3 x & =-2-8 & & \text { Line 2 } \\ 5 x & =-10 & & \text { Line 3 } \\ x & =\frac{-10}{5} & & \text { Line } 4 \\ x & =-2 & & \text { Line 5 }\end{aligned}$




\section{Extract 1}

Interviewer: Okay. Okay, talk to me about the next sum [Refers to the equation $2 x+8=3 x-2$ ].

Sheena: [Silence]. Um ... here was ... here is variables on this side and here is numbers without, so you first had to um take ... put it on the right spot. [Points to +8 on left-hand side of Line 1, then -8 on right-hand side of Line 2]

Interviewer: Right.

Sheena: $\quad$ So this was minus ... negative three [points to $-3 x$ in Line 1] so we had to make it plus, so it was $2 x$ plus $3 x$. And this stays negative two, but this must be -8 [points to +8 on the left-hand side of Line 1] because you're putting it on this side [points to right-hand side].

Interviewer: Okay. Why do you do that, hey? Do you know? Sheena: Why do I do what?

Interviewer: Why do you change the sign when you take it over?

Sheena: Because that's how I was taught.

Words: This level of analysis draws on a functional perspective of language in mathematics, as used by Morgan (1998) and Sfard (2008). From this perspective, language use in mathematics is not neutral, but performs a particular function in mathematical discourse. We categorised a learner's language use according to its linguistic features, and the related meaning of these features in the context (Morgan, 1998, Sfard, 2008), as shown in Table 4.

In Extract 1, Sheena uses a combination of mathematical and colloquial words to reference entities. She refers to 'variables' but refers to constants as 'numbers without'. When she says 'You first had to put it on the right spot' she uses an adverb of time ('first') to suggest she is following steps. The material process verb 'put' together with the adverbial phrase of place ('on the right spot') points to how she, as the subject of the sentence and the doer of action, is using spatial arrangement to reorganise entities as part of her procedure for solving the equation. Indication of her obedience to authority lies in her use of high modality verbs such as 'must' and 'had to'. This obedience to authority of the teacher is confirmed in her reason for 'changing the sign', where she makes a direct reference to how she had been taught.

Visual mediators: The visual mediators, that is the discursive prompts used in the interviews to communicate about the operations and relationships (Sfard, 2008), are restricted to

TABLE 4: Linguistic features and their associated meanings.

\begin{tabular}{ll}
\hline Linguistic feature & Meaning in mathematical discourse \\
\hline Nouns & Mathematical vs. colloquial words \\
Verb processes & Keywords with relational vs. material processes \\
Modal auxiliary verbs & $\begin{array}{l}\text { Verbs with high modality (e.g. 'must') indicate obedience } \\
\text { to authority }\end{array}$ \\
Subject and object & $\begin{array}{l}\text { Keyword as subject or object vs. person as subject or } \\
\text { object }\end{array}$ \\
Voice & $\begin{array}{l}\text { Passive vs. active voice } \\
\text { Adverbs }\end{array}$ \\
$\begin{array}{l}\text { Adverbs of place for spatial arrangement, adverbs of time } \\
\text { for sequential action }\end{array}$ \\
Articles & Keywords prefaced with article \\
Pronouns & Reference pronouns for keywords \\
\hline
\end{tabular}

symbols, integers and operational signs in algebraic expressions and equations.

In Extract 1 Sheena makes frequent reference to 'sides' of the equation as she reorganises the entities so that the variables are on the left-hand side and the constants are on the righthand side. Each term is a discursive prompt that visually mediates the position of the entities. Sheena frequently points to terms in the equation (referencing them as 'this'), with a focus on the operational signs. Her talk indicates that the sign is an independent visual mediator because whether she 'makes it a plus' or it 'stays negative' is affected by where she 'puts' the term.

Narratives: For this analysis narratives were categorised either as descriptions of entities and relations between them, or as narratives about actions with or by entities. We used a learner's discourse in the transcript to re-present the narratives. For example, the statement 'but this must be negative 8 because you're putting it on this side' was re-presented as " +8 " becomes " -8 " when it is shifted to the other side of the equal sign'. Where appropriate, the source of the narrative was included. For this narrative the source is 'spatial arrangement', which is not an endorsed narrative in mathematical discourse.

Routines and realisation trees: The realisation routine is the set of sequential steps for solving an equation; each step in the solution process is a realisation based on signifiers from the previous realisation. We remind the reader that the visual mediators are signifiers that mediate meaning between one entity and another. Sfard (2008) posits that truly explorative thinking would be marked by a learner's ability to access more than one way to find the solution to the equation. This has been illustrated in the realisation tree in Figure 1. In this study all learners only had one branch, which was to be expected, given that the preferred teaching strategy for solving equations is the algebraic algorithm. Thus our focus when looking at learners' realisation trees in the analysis is on how the visual mediators signify meaning between one entity and another for the learners.

The learners' written solution, speech and gestures were used to interpret the realisation routines, which were then used to construct the realisation trees - the visual representations of the learners' personal constructions of the 'mathematical objects'. In Figure 3 we illustrate Sheena's discursive construction of the solution of the equation $2 x+8=-3 x-2$ as a realisation of a narrative about the functions $f(x)=2 x+8$ and $g(x)=-3 x-2$.

Sheena's written solution, speech and gestures were used to describe her realisation routine (Figure 3, column 2), which was to perform a number of actions with the entities, based on the visual mediators (circled in column 3), with each of these sub-nodes labelled 1-a, 1-b, etc. Column 4 shows her realisation tree, with all nodes and sub-nodes included. 
TABLE 5: Grade 8 and Grade 9 learner scores on equations from their written assessment task.

\begin{tabular}{|c|c|c|c|c|c|c|c|c|c|c|c|c|c|c|c|}
\hline \multirow[t]{2}{*}{ Equation type } & \multicolumn{11}{|c|}{ Grade 8 learners } & \multicolumn{4}{|c|}{ Grade 9 learners } \\
\hline & Sheena & Joshua & William & Nadia & Shakiera & Fatima & Erin & Carla & Gadija & Alison & Thomas & Kabelo & Emily & Tumisho & Zahir \\
\hline$a x+b=c$ & $3 / 3$ & $3 / 3$ & $3 / 3$ & $1 / 3$ & $3 / 3$ & $3 / 3$ & $3 / 3$ & $3 / 3$ & $3 / 3$ & $3 / 3$ & $3 / 3$ & $3 / 3$ & $3 / 3$ & $3 / 3$ & $3 / 3$ \\
\hline$a x+b=c x+d$ & $4 / 4$ & $4 / 4$ & $4 / 4$ & $0 / 4$ & $4 / 4$ & $4 / 4$ & $3 / 4$ & $4 / 4$ & $4 / 4$ & $4 / 4$ & $4 / 4$ & $5 / 5$ & $5 / 5$ & $5 / 5$ & $5 / 5$ \\
\hline$a(x+b)=c+d(x+e)$ & $5 / 5$ & $2 / 5$ & $5 / 5$ & $5 / 5$ & $1 / 5$ & $1 / 5$ & $5 / 5$ & $3 / 5$ & $5 / 5$ & $0 / 5$ & $5 / 5$ & $5 / 5$ & $1 / 5$ & $4 / 5$ & $5 / 5$ \\
\hline Percentage scored & 100 & 75 & 100 & 50 & 67 & 67 & 92 & 83 & 100 & 58 & 100 & 100 & 69 & 92 & 100 \\
\hline
\end{tabular}

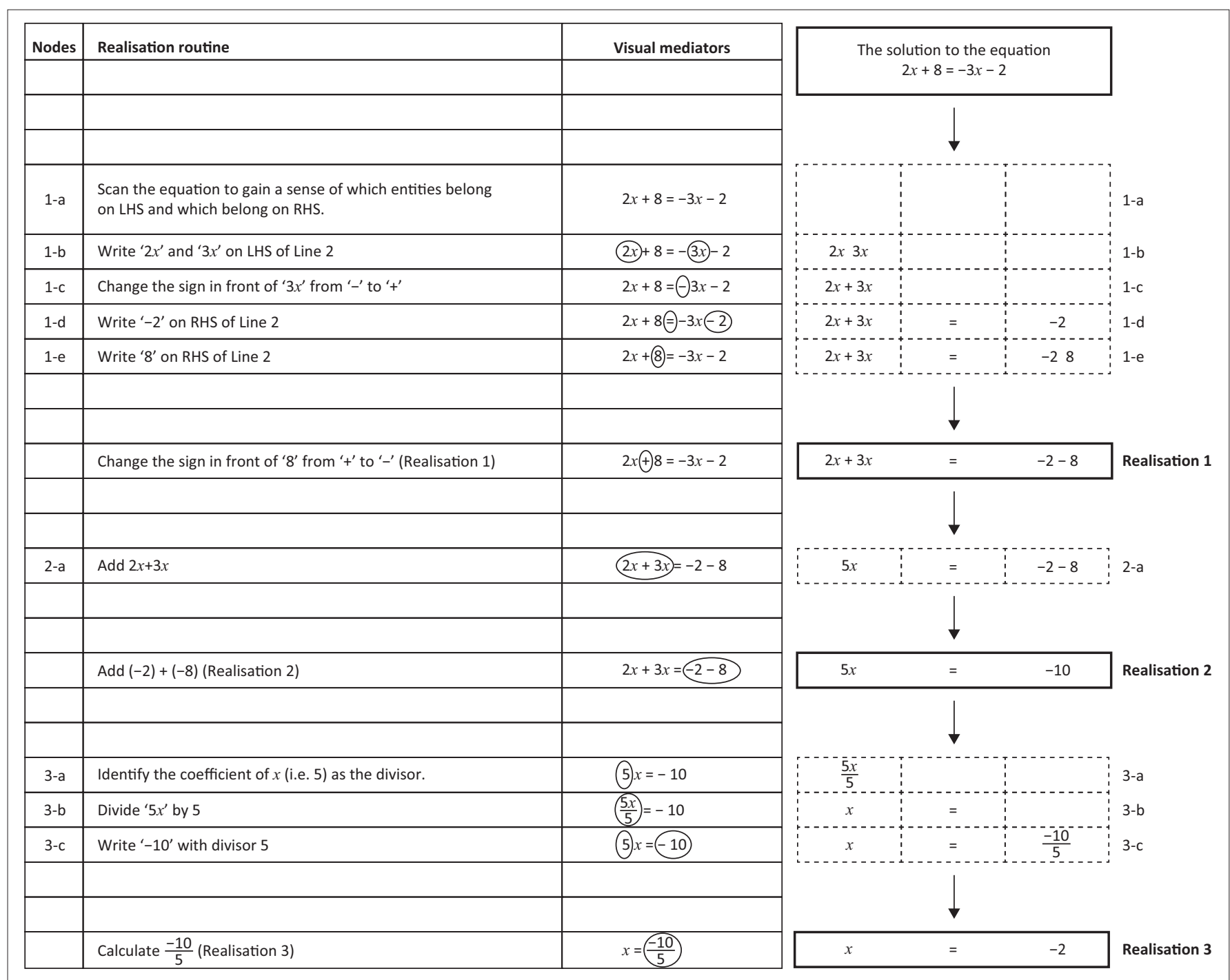

Source: Roberts, A. (2016). A study of Grade 8 and 9 learner thinking about linear equations, from a commognitive perspective. Unpublished master's thesis, University of Cape Town, Cape Town, South Africa (p. 49). Retrieved from https://open.uct.ac.za/handle/11427/20627

Note: LHS and RHS refer to the left-hand side and right-hand side of the equation respectively.

FIGURE 3: The re-presentation of Sheena's realisation routine and tree for the solution to the equation $2 x+8=-3 x-2$.

Some might argue that Sheena's realisation tree (Figure 3) illustrates a mathematically endorsable solution to the equation. While it can be argued that her narrative about the actions for obtaining Realisation 1 are mathematically endorsable, we find no evidence of explorative discourse in her explanation. The first step in her procedure is an action with $3 x$, which she described as having to 'put it on the right spot' (sub-node 1-b). Her action with $3 x$ was separated from her action with the negative sign, which was to 'make it a plus' (sub-node 1-c). Nodes 1-d and 1-e illustrate a similar procedure for the completion of Realisation 1. We conclude that her realisation routine is thus not endorsable.

\section{Level 2 analysis}

The Level 2 analysis uses the perceptible features of a learner's discourse about linear equations recorded at Level 1 (word and mediator use, narratives and realisations) to classify the routines using Sfard's (2008) seven features of ritualised and explorative discourse (Table 2). The detailed list of indicators for these features is available in Roberts (2016, p. 91).

Due to space limitations, in this article we illustrate how we utilise the level 1 analysis of Sheena's solution for $2 x+8=-3 x-2$ presented thus far, for the first two features 
of discourse, namely the degree of objectification and the extent to which the narrative is endorsed. We note, however, that whether a learner's discourse is explorative or ritualistic at the time of the interview can only be determined after the full analysis.

The level 1 analysis suggests that Sheena uses mathematical and non-mathematical words as part of phrases in her routines, and hence in a phrase-driven way (indicator 1.2.1), as illustrated in the statement 'here is variables on this side and here is numbers without'. Her use of material process verbs in the active voice and pronouns indicates that she performs actions with and by mediators as disobjectified entities (indicator 1.2.2). The adverbs of place indicate the spatial arrangement of these entities (indicator 1.2.2) and the material process verbs suggest they actively move to different sides of the equation, thus disrupting horizontal equivalence (indicator 1.2.3). As expected, her realisation tree has only one branch, an algebraic branch (indicator 1.2.5). The level 1 analysis suggests that Sheena's narrative about how entities 'move' horizontally relies on the spatial arrangement and is not endorsable (indicators 1.2.3, 2.2.1). In terms of vertical equivalence, we note that some of her actions and narratives for obtaining realisations are endorsable, but the overall the solution is not (indicator 1.2.4). The indicators identified here, together with others in the full analysis of Sheena's interview, lead us to conclude that her discourse at this moment is ritualised.

\section{Validity}

According to Maxwell (1992), 'validity' in qualitative research refers to the relationship between the research account of what happened and the real-life situation (in this case, the interview). For 'descriptive validity' (Maxwell, 1992, p. 285) in this research, speech and gestures in the recordings were accurately transcribed at a level of detail appropriate for the research focus, and transcripts were refined during the analysis through revisiting the recordings and engagement between the authors. The 'theoretical validity' (Maxwell, 1992, p. 291) of Sfard's (2008) theory of commognition in this research is borne out by its use by a growing group of researchers, as reviewed in this article. In addition, in this article we define and illustrate the use of Sfard's tools specifically to study thinking about linear equations.

Since this is a small-scale qualitative study, the findings are not generalisable to any other group of learners or topic in mathematics. However, the analytic tools provide a rich description of the learners' discourse, allowing the broader community to decide to what extent the findings may or may not apply in other contexts.

\section{Findings}

The starting point for the investigation reported in this article was the set of findings in Table 5, which indicates the learners' scores on the set of equations used in the research. These findings suggest that many of the learners know how to solve these equations. The table shows that not all learners performed perfectly. This was useful for the study because, while initially we hypothesised that the learners whose solutions attracted full marks would be thinking exploratively, our findings showed that this was not the case. Most learners lost marks through computational errors.

In this section we present the results of applying Sfard's (2008) commognitive framework to each learner's discourse in the interview. We structure these results according to Sfard's seven features of explorative and ritualised discourse (Table 2). The study indicates that learners' discourse when talking about their solutions to the linear equations was ritualised, not explorative. However, the detailed analysis showed subtle differences in the ritualised discourse across learners. To illustrate these differences we draw on a selection of learners in reporting on the findings of the study. Note that although we only report on a selection of findings, we analysed the discourse of all 15 learners, including Sheena.

\section{Feature 1: Degree of objectification of learners' discourse}

There are some findings that show similar responses from the learners in the study. One of these is the way learners talk about positive integers (whole numbers) compared to the way they talk about negative integers, variables and algebraic terms. All learners talk about positive integers as mathematical objects in their own right, which indicates objectified word use. However, how they talk about negative integers and algebraic terms suggests differences in their thinking.

Another finding is that all learners use words in a routinedriven way in the context of their routines. This is illustrated by Carla whose discourse is typical of many Grade 8 learners. When solving the equation $2 x+8=-3 x-2$, her mediator and word use for the sum ' $-2-8$ ' points to routine-driven, disobjectified use of mediators and words on one line of an equation: 'I moved this ... $-3 x$ over but made it a ... a positive number ... because of the ... the negative and positive ... the opposite'. Carla uses the reference pronoun 'this' for the keyword ' $3 x^{\prime}$ and talks about the material action of personally 'moving' this entity 'over' (indicators 1.2.2 and 1.2.3). She also uses the colloquial word 'opposite' instead of talking about inverse operations as the curriculum specifies (indicator 1.2.1). There is little difference between the discourse of the Grade 8 and Grade 9 learners in this respect. Kabelo (Grade 9) explains part of his routine for solving the equation $6 x-12=2 x+4$ : 'Then I took this negative 12 , then I put it on the right-hand side. Then it became positive.' On enquiry from the interviewer about why he 'put it' on the right-hand side, he explains that 'it doesn't have a $x$, and this one [points to 4 on right-hand side in Line 2] doesn't have a $x^{\prime}$. His discourse is characterised by routine-driven actions with entities and his narrative is not endorsed.

However, there are nuances between learners in the degree of objectification evident in their talk. In the methodology section, we suggested that Sheena's (Grade 8) use of nouns, material process verbs in the active voice, pronouns, and 
adverbs when solving the equation $2 x+8=-3 x-2$ points to phrase-driven use of keywords. This, since she uses phrases constantly in her explanations (indicator 1.2.1) and performs actions with and by mediators as disobjectified entities (indicator 1.2.2). Yet in her interview we also identify instances of objectified talk about integers (indicator 1.1.2). For example, in this narrative she does not split the integers into separate entities, and the relationship between them is endorsable (indicator 2.1.2): ' -2 times 6 is -12 . And -1 times 1 is $-1^{\prime}$. Similarly, Kabelo (Grade 9) describes a routine in a mathematically endorsed way using mathematical objects: ' -2 times $x$ is equal to $-2 x$. And -2 times +3 is equal to -6 '.

There are also nuances in learners' perception of the equal sign. We report on perceptive differences among three Grade 8 learners. Erin relates the equal sign to a calculation: 'If you calculate something, that (points to equal sign) will indicate that you get your answer'. Fatima's use of adverbs of place shows how the equal sign is a spatial organiser for entities (indicator 1.2.3): 'Um ... the constants on the one side and the variables on the other side.' Nadia, on the other hand, uses gesture to suggest that the left-hand side and right-hand side of the equation are equivalent: 'It means that (points to lefthand side) is equal to that (points to right-hand side)'. Although she has not expressed herself in words, her explanation relating to horizontal equivalence between the two functions is endorsable (indicator 1.1.3). Of the four Grade 9 learners three explain that the equal sign signified an equation. The discourse of the fourth learner, Emily, shows that she sees the horizontal equivalence imposed by the equal sign: 'the one side must ... must have the same value as the other side'. She is also the only learner in the study whose solution to the equation $4 m=2 m$ is endorsable.

Overall, we note that no learner in the study uses horizontal or vertical equivalence as a signifier or source of the narrative, except when prompted to do so (indicators 1.2.3, 1.2.4 and 1.2.5). An example of this is how, through prompting, Tumisho (Grade 9) explains that there is equivalence between ' $2 x$ ' and ' 6 ' in the equation $2 x+7=6+7$ :
Interviewer:
Can you, just looking at this [Waves hand across both sides of the equation $2 x+7=6+7] \ldots$ what's .... what's $2 x$ equal to?
Tumisho: $\quad \operatorname{Um} \ldots 2 x \ldots$ um ... equals to um ... I think equals to 3 .
Interviewer: $2 x$ ?
Tumisho: Yes
Interviewer: And what's $x$ equal to if $2 x$ is equal to 3 ?
Tumisho: [Silence]
Interviewer: Can you see that $2 x$ is equal to 6? [Points simultaneously to ' $2 x$ ' on left-hand side and ' 6 ' on right-hand side]
Tumisho: Yes. So $x \ldots$... [points to ' $2 x^{\prime}$ ] ... so $x$ will be 3 because 2 times 3 will get 6 .

We also presented learners with different versions of the equation ' $2 x+7=13^{\prime}$, namely ' $2 x+7=6+7$ ' and ' $13=2 x+7$ ' to explore whether learners use horizontal equivalence as a resource for solving linear equations, which bears further discussion. Some learners use horizontal equivalence to show that ' $2 x^{\prime}$ and ' 6 ' are equivalent in the equation $' 2 x+7=6+7{ }^{\prime}$, and to see that ' $2 x+7=13^{\prime}$ and ' $13=2 x+7{ }^{\prime}$ are equivalent equations and thus that the solution is the same for both (indicator 1.1.3). William's reasoning is similar to Sheena's when explaining that ' $2 x^{\prime}$ ' was equal to ' 6 ' in the equation ' $2 x+7=6+7$ ': 'that six represents that $2 x$, so $\ldots$ it equals two times three'. Many learners revert to finding the solution for ' $2 x+7=6+7$ ' (indicator 1.2.4): 'If I carry the seven over ... and then the difference between seven and ... negative seven is nought'. When repeating the calculations, these learners often make computational errors because the variable is not on the left-hand side. None of them question that their solution is different to that of the equivalent equation. These findings suggest that teacher prompts could potentially shift learners to think exploratively. Where learners do not respond favourably to such prompts, as was the case with learners who reverted to finding the solution, teachers could possibly change their teaching strategies to encourage a shift to explorative thinking.

When solving the given equations in the interview no learner produces endorsable narratives that reference vertical equivalence. Rather, Shakira's narrative in which her mediator and word use interrupts equivalence is typical of all learners: 'And then you have $2 x$. I took the $x$ down... and I ... move that [points to ' 2 ' of ' $2 x^{\prime}$ ' on left-hand side] over to there [points to right-hand side of next line]'. In this excerpt the adverb of place 'down' indicates material movement ('took') of 'the $x^{\prime}$, her gesture shows where she materially 'moved' ' 2 ' to the right-hand side of the next line, and the adverb of time 'then' refers to the sequence of actions (indicator 1.2.3).

To determine whether learners use vertical equivalence as a resource, learners were asked about the significance of substituting the solution into the original equation. It is curious that no learner shows familiarity with the notion of substitution, as this is a topic in the curriculum. Therefore it was not productive to analyse their responses, but we note that substitution in relation to solving equations could encourage relational thinking in learners - and particularly in the development of their thinking about horizontal and vertical equivalence.

Finally, in terms of degree of objectification, we note that the realisation trees for all learners only have one branch, an algebraic branch (such as Sheena's in Figure 3). Thus, the equation does not signify more than one realisation for any learner (indicator 1.2.5). Based on our evidence presented in this section we conclude that the discourse of all learners is predominantly disobjectified (indicator 1.1). This is not a criticism, because, as noted, learner orientation to the solution of linear equations is to the algebraic procedure.

\section{Feature 2: Endorsed narratives}

We have argued that the only mathematical objects students regularly talk about are positive integers, thus it is to be 
expected that their endorsed narratives are limited. All learners produce endorsed narratives about operations with positive integers (whole number arithmetic) (indicator 2.1.3). For example, explaining his calculation ' $6 x-2 x^{\prime}$ in the equation ' $6 x-2 x=12+4$ ', Zahir says: 'Then I minus um ... 2 from ... from 6 , and it becomes 4 '. Although Zahir writes the solution as ' $4 x^{\prime}$, he only talks about the whole numbers.

Besides the endorsable narratives about positive integers, learners produce narratives that are not endorsed, about actions with disobjectified entities (indicator 2.2.1). They also use spatial arrangement and visual appearance as the source of the narrative (indicator 2.2.2). In the example that follows, Erin uses spatial arrangement on the signifier ' $2 x=6$ ' to realise $x=\frac{6}{2}$. She performs separate actions on ' 2 ' and ' $x$ ': 'You put the $x$ at the bottom of 6 and bring over the 2 because ... you must get a equal sign to $x^{\prime}$.

However, as with words and visual mediators, there are differences in the degree to which their narratives are endorsable. Some learners structure their thinking by talking about the relationship between objects in a phrase-driven way. For example, Sheena says: 'Negative two times three will give you negative six'. Others produce endorsable narratives about the nature of integers, variables and equations (indicator 2.1.1). An example is Tumisho's narrative about the equation ' $2(4 x-5)-(3 x+6)=-2(x+3)^{\prime}$. In response to an interview prompt about an arithmetic error, he points to the negative sign in the term ' $-(3 x+6)^{\prime}$ and explains: 'there is a one there that you can't see'. Yet, he still produces the unendorsed realisation ' $-3 x+6$ ' (indicator 2.2.1). This example illustrates that although some learners recall previously endorsed narratives about mathematical objects, they do not necessarily link such narratives to endorsed actions with these objects. This is a feature of ritualised discourse. No learner uses endorsed narratives about objects as the source of their realisations (indicator 2.2.2), unless prompted to do so (as in Tumisho's case here).

Based on the evidence presented here, we argue that the extent to which learners' narratives are endorsable is not characteristic of explorative discourse.

\section{Feature 3: Closing condition}

The analysis shows that no learner sees the closing condition as being to produce an endorsed narrative about the original equation. For all learners the closing condition is that the final realisation should have the appearance ' $x=$ [some number]' (indicator 3.1). This is particularly evident in their solution of the equation that does not have a constant term. For example, initially Nadia (Grade 8) gives her solution to the equation ' $2 x=-3 x^{\prime}$ as ' $-1 x^{\prime}$. She justifies her solution: ' $\mathrm{I}$ think three minus two is one, right? ... Because the signs are different'. But later she changes her mind: 'I don't think you should put $x$ there, because you're trying to solve $x^{\prime}$. Nadia's need to have an integer as a solution makes her discard the variable. There are numerous similar narratives in the data set about the closing condition for this equation. To investigate further the interviewer prompted learners to think about 'zero' as a solution. Few learners could use the prompts to conclude that the variable would equal zero, with most wanting the solution to be a positive integer. In the words of Zaahir (Grade 9), 'There must be a constant or something'. However, prompting proved to be a good strategy to get some learners to think in an explorative way. We present an excerpt from the interview with Joshua (Grade 8) as a typical example of this. His initial response when asked to solve the equation $4 m=2 m$ was 'I don't think I can, Miss. Because I never ... my miss didn't give us this sums yet Miss'. The interviewer then prompted him to consider zero as a solution. Parts of the interaction are presented below:

$\begin{array}{ll}\begin{array}{l}\text { Interviewer: } \\ \text { Joshua: }\end{array} & \begin{array}{l}\text { This } m \text { can } m \text { be zero? } \\ \text { Miss? }\end{array} \\ \text { Interviewer: } & \begin{array}{l}\text { Mm. Which } m \text { ? [Silence] Do the two } m \text { s have the } \\ \text { same value? }\end{array} \\ \text { Joshua: } & \begin{array}{l}\text { I don't think so, Miss, because this is a higher } \\ \text { number [points to } 4 m \text { ] than this [points to } 2 m \text { ] }\end{array} \\ \text { Interviewer: } & \text { Oh okay. So how does that affect the value of } m ?\end{array}$

Initially, Joshua is confused about substituting zero for $m$, but when that is clarified, the interview ends on a positive note:

$\begin{array}{ll}\text { Interviewer: } & \text { And if } m \text { was zero? } \\ \text { Joshua: } & \text { Then the whole sum is zero, Miss. } \\ \text { Interviewer: } & \text { Yes ... so could } m \text { be zero? } \\ \text { Joshua: } & \text { Yes, Miss then it come to the same values. } \\ \text { Interviewer: } & \text { On both sides? } \\ \text { Joshua: } & \text { Yes, Miss. }\end{array}$

\section{Feature 4: For whom the routine is performed}

There is no evidence that the learners' discourse is characterised by internal persuasion based on mathematical properties of the object. Rather, the learners' regular use of adverbs of time and high modality verbs suggests that they solve the equations for, and with others (indicator 4.2). Typical is Sheena's talk, which contains both the adverb of time 'always' and the high modality auxiliary verb 'must', suggesting that visual appearance is the source of the narrative about their actions: 'The last sum must always end with the variable'.

Who are the 'others' whose authority drives learners? There is almost no reference to the teacher as the authoritative source of their narrative, except for Zahir who, when faced with the equation ' $4 m=2 m^{\prime}$ explains: 'My ma'am never gave me a sum like this before. There must be a constant or something'. However, learners defer to other people as the authority. Although they didn't know the interviewer prior to the interview, many learners see her as a source of authority for solving the equation ' $4 m=2 m$ '. This is particularly evident when she provides scaffolding by asking whether ' $m$ ' could be zero, a cue that many assume to mean that the solution had to be zero. Yet only two learners could endorse this narrative. 


\section{Feature 5: By whom is the routine performed?}

The analysis shows that no learner solves the equations independently, using 'thoughtful imitation' (Sfard, 2008, p. 249). Rather, learners follow the metarules of others (indicator 5.2.2). Sheena's obedience to a rule is suggested by the high modality verb 'must': 'The negative twenty-one must change to a positive twenty-one'. Learners also use non-mathematical sources such as visual mediators and spatial organisation as the source of narratives (indicator 5.2.1). Some learners defend their realisations in an endorsable way, but only when prompted by the interviewer (indicator 5.2.1).

\section{Feature 6: Level of flexibility}

This feature of the learners' discourse was analysed using the alternate representations of the equation ' $2 x+7=13^{\prime}$, namely $' 13=2 x+7{ }^{\prime}$ and ' $2 x+7=6+7$ '. The aim was to determine whether their concept of equation could accommodate these modifications. As indicated, a minority of learners use horizontal equivalence flexibly to show that ' $2 x^{\prime}$ equals ' 6 ' in the equation ' $2 x+7=6+7$ '. Most often, though, learners revert to the routine for finding the solution (indicator 6.2).

\section{Feature 7: Level of correctibility}

The measure of correctibility is related to learner errors, so evidence for this feature depends on whether learners make errors in their solutions. These errors are limited to arithmetic errors (identified in the teachers' assessment) and errors relating to the structure of the equation. Nadia, Carla, Kabelo and Emily all correct arithmetic errors, although Nadia and Emily miss some of these errors. In addition, both Nadia and Alison have errors relating to horizontal equivalence that they do not correct, even with prompting. As an example, we present Alison's solution to the equation ' $2 x+8=-3 x-2$ ', for which she obtained full marks in the assessment task:

$$
\begin{aligned}
2 x+8 & =-3 x-2 & & \text { Line } 1 \\
2 x+3 x & =-2-8 & & \text { Line } 2 \\
5 x & =-10 & & \text { Line } 3 \\
\frac{10}{5} & =-2 & & \text { Line } 4
\end{aligned}
$$

Alison's realisation from the signifier ' $5 x=-10$ ' is ' $\frac{10}{5}=-2$ ', yet when asked what the value of $x$ is, she simply responds: 'Where's $x$ Miss? I think the $x$ fell away'.

\section{Discussion and conclusions}

The research in this article emerged out of a concern expressed in the literature and experienced in the first author's practice - that learners who may achieve above average assessment scores when solving linear equations have difficulty using mathematically valid resources to explain why or when to use a particular strategy. In this article we use Sfard's (2008) 'penetrating' theory of commognition, located in a participationist view of learning, to understand these aspects of thinking about linear equations. The analysis presented here is limited in the sense that it focuses on learner discourse at one moment in time rather than over time (compare Heyd-Metzuyanim, 2015; Nachlieli \& Tabach, 2012) and it does not include a study of the related teacher discourse (compare Heyd-Metzuyanim \& Graven, 2016; Sfard, 2017). However, our use of Sfard's concepts specifically for the study of discourse about linear equations (presented in the detailed Table 2) is productive for drilling down to identify the similarities and also some nuanced differences in the discourse of 15 learners.

The evidence presented in this article suggests that the discourse of the learners - both Grade 8 and Grade 9 - can be described as ritualistic rather than explorative. The only mathematical objects learners regularly produce are endorsed narratives about positive integers. Mostly they produce unendorsed narratives about disobjectified entities, including actions with these entities. No learner talks about the properties of number or axioms (like inverse operations) as a source of the narrative for solving linear equations. Rather, they perform their routines for and with others using the rules of others, visual appearance and spatial organisation as the source of their narratives. Their realisation trees illustrate that they often use non-mathematical entities as visual mediators. For all learners the closing condition is the appearance of the solution. In addition, learners have little or no flexibility. The limited evidence available points to a reasonable level of correctibility regarding arithmetic operations, but not regarding the structure of their solutions.

The analysis of these interviews, conducted in the eighth month of the school year, indicates that curriculum requirements for Grade 8 and Grade 9 are not met. By this time learners should, especially at Grade 9 level, have progressed from 'a view of Mathematics as memorised facts and separate topics to seeing Mathematics as interrelated concepts and ideas represented in a variety of equivalent forms' (DBE, 2011, p. 21). While the curriculum specifications are not in question, we agree with Gcasamba (2014) who suggests that the curriculum guidelines may promote such ritualistic discourse. For example, the teaching guidelines section of the curriculum document provides teachers with examples of linear equations of different complexity levels and 'steps' for solving each (DBE, 2011, p. 94). These may promote reliance on the visual appearance of a problem for the selection of the routine.

The findings in this article - presented using a commognitive approach to thinking - are consistent with the views of Linchevski and Livneh (1999) and Hoch and Dreyfus (2004) that learners regarded as not having what they call structure sense rely on other people's routines rather than on the properties of number or functions to solve linear equations. It also supports Hoch and Dreyfus's (2006) claim that there is no correlation between learners' structure sense and their manipulation skills. Indeed, these findings show that for learners whose routines for solving linear equations yield above average scores on written assessments, the mathematical objects they work with are restricted to positive 
integers. The description of how these learners spatially arrange disobjectified entities as part of their routines resonates with how De Lima and Tall $(2008$, p. 4) use the concept of embodiment to describe how learners move terms of an equation.

While the findings in this article resonate with the findings of other studies, the analytic tools have produced a particular nuanced account of differences in the ritualised discourse of learners that other studies have not shown. Firstly, although most learners use colloquial words or talk about disobjectified entities, some use keywords in a phrase-driven way to produce phrases that are mathematically endorsable. Secondly, while most learners only produce endorsed narratives about positive integers, some also produce endorsed narratives about positive and negative integers, algebraic terms and the structure of equations. Thirdly, we have argued that all learners use spatial arrangement and physical appearance as sources of narratives and perform routines for and with others. Yet the prompting that took place in the interviews led to some learners producing endorsed narratives as sources and showing internal persuasion. Furthermore, some learners have the flexibility to see the structure of the equation as a signifier for their realisation, whereas others rely solely on the routine.

These observed differences do not provide sufficient evidence to argue that some of these learners are in transition from ritualised to explorative discourse, that is, that they are 'thoughtful imitators' (Sfard, 2008, p. 249) in the sense that they have thought about their routines and tried to make sense of things for themselves. Yet some learners respond positively to prompts, and then try to make sense of their routines using endorsed narratives about mathematical objects. Thus, these prompts could be a possible lever for shifting learners towards explorative discourse. This leads to recommendations for practice and research, which we turn to next.

Since teachers' discourse has been shown to impact on learners' discourse (Heyd-Metzuyanim \& Graven, 2016; Tabach \& Nachlieli, 2011), teachers' understanding of these nuances in learners' discourse could be used as points of engagement in teacher professional development. There is also potential in this process to explore how the prompts used as a research tool in this study might be taken into the classroom and used to shift learner thinking. Prompts that encourage learners to explain their thinking, revisit their solutions, and invite alternative approaches such as substitution might be used in whole class and small group classroom interactions. We also recommend a focus in this professional development on links between the algebraic format of linear equations and other representations of functions like flow diagrams, tables and ordered pairs. In this article we have attributed the single-branch realisation trees of the learners in this study to the commonly used algebraic approach used in teaching. Yet the school curriculum does prescribe other approaches, for example using tables of ordered pairs. We argue that the establishment of these links in the classroom creates opportunities for learners to shift to explorative thinking about linear equations, especially when confronted with unfamiliar problems. We believe there is scope to twin such professional development recommended here with a wider research study, using the analytic tools presented in this article, that explores learner discourse on linear equations over time.

\section{Acknowledgements}

Data for the study on which this article is based were made possible by the Schools Development Unit at the University of Cape Town. We also wish to acknowledge the Centre for Higher Education Development and the Research Office at the University of Cape Town for writing support for the article.

We acknowledge the personal communication from Anna Sfard during the development of the study on which this article is based.

\section{Competing interests}

The authors declare that they have no financial or personal relationships that may have inappropriately influenced them in writing this article.

\section{Authors' contributions}

A.R. was the researcher, and K.1.R. supervised the research. The writing of this article was a joint task.

\section{References}

Adler, J. (2011). Mathematics for teaching: What is it and why is it important that we talk about it? Pythagoras, 62, 2-11. https://doi.org/10.4102/pythagoras.v0i62.109

Adler, J., \& Pillay, V. (2017). Mathematics education in South Africa. In J. Adler \& A. Sfard (Eds.), Research for educational change: Transforming researchers' insights into improvement in mathematics teaching and learning (pp. 9-24). Abingdon: Routledge.

Alibali, M.W., Knuth, E.J., Hattikudur, S., McNeil, N.M., \& Stephens, A.C. (2007). A longitudinal examination of middle school students' understanding of the equal sign and equivalent equations. Mathematical Thinking and Learning, 9(3), 221-247. https://doi.org/10.1080/10986060701360902

Asquith, P., Stephens, A.C., Knuth, E.J., \& Alibali, M.W. (2007). Middle school mathematics teachers' knowledge of students' understanding of core algebraic concepts: Equal sign and variable. Mathematical Thinking and Learning, 9(3), 249-272. https://doi.org/10.1080/10986060701360910

Barahmand, A., \& Shahvarani, A. (2014). Students' equation understanding and solving in Iran. REDIMAT, 3(2), 169-185. https://doi.org/10.4471/redimat.2014.48

Berger, M., \& Bowie, L. (2012). A course of functions for in-service mathematics teachers: Changing the discourse. Education as Change, 16(2), 217-229. https:// doi.org/10.1080/16823206.2012.745751

Bogdanova, M. (2012). The role of the teacher in object-level and meta-level learning. Unpublished master's thesis, University of the Witwatersrand, Johannesburg, South Africa.

Brodie, K. (2010). Teaching mathematical reasoning in secondary school classrooms. New York, NY: Springer. https://doi.org/10.1007/978-0-387-09742-8

Caspi, S., \& Sfard, A. (2012). Spontaneous meta-arithmetic as a first step toward school algebra. International Journal of Educational Research, 51-52, 45-65. https://doi.org/10.1016/j.ijer.2011.12.006

Clark, R. (2014). Exploring and describing the growth points of learners as they encounter functions in equation form. Unpublished master's thesis, University of the Witwatersrand, Johannesburg, South Africa.

De Lima, R.N., \& Tall, D. (2008). Procedural embodiment and magic in linear equations. Educational Studies in Mathematics, 67(1), 3-18. https://doi.org/10.1007/ s10649-007-9086-0

Department of Basic Education. (2011). Curriculum and assessment policy statement Grades 7-9 Mathematics. Pretoria: DBE. Retrieved from https://www.education.gov. za/Portals/0/CD/National\%20Curriculum\%20Statements\%20and\%20Vocational/ CAPS\%20SP\%20\%2OMATHEMATICS\%20GR\%207-9.pdf?ver=2015-01-27-160141-373 
Essien, A., \& Setati, M. (2006). Revisiting the equal sign: Some Grade 8 and 9 learners' interpretations. African Journal of Research in Science, Mathematics and Technology Education, 10(1), 47-58. https://doi.org/10.1080/10288457.2006.10740593

Filloy, E., \& Rojano, T. (1989). Solving equations: The transition from arithmetic to algebra. For the Learning of Mathematics, 9(2), 19-25.

Fleisch, B. (2008). Primary education in crisis: Why South African schoolchildren underachieve in reading and mathematics. Cape Town: Juta.

Gardee, A., \& Brodie, K. (2015). A teacher's engagement with learner errors in her Grade 9 mathematics classroom. Pythagoras, 36(2), Art.\#293. http://dx.doi. org/10.4102/pythagoras.v36i2.293

Gcasamba, L. (2014). A discursive analysis of learners' mathematics thinking: The case of functions. Unpublished master's thesis, University of the Witwatersrand, Johannesburg, South Africa.

Graven, M.H. (2014). Poverty, inequality and mathematics performance: The case of South Africa's post-apartheid context. ZDM: The International Journal on Mathematics Education, 46, 1039-1049. https://doi.org/10.1007/s11858-0130566-7

Gripper, D. (2011). Describing and analysing Grade 10 learners' descriptions of the syntactic resources they use transform expressions. In H. Venkat \& A.A. Essien (Eds.), Proceedings of the 17th Annual National Congress of the Association for the Mathematics Education of South Africa (pp. 81-92). Johannesburg: AMESA.

Hall, R.D.G. (2002). An analysis of errors made in the solution of simple linear equations. Philosophy of Mathematics Education Journal, 15, 1-64. Retrieved from http://citeseerx.ist.psu.edu/viewdoc/summary?doi=10.1.1.9.4056

Herscovics, N., \& Linchevski, L. (1994). A cognitive gap between arithmetic and algebra. Educational Studies in Mathematics, 27(1), 59-78. https://doi. org/10.1007/BF01284528

Heyd-Metzuyanim, E. (2015). Vicious cycles of identifying and mathematizing: A case study of the development of mathematical failure. Journal of the Learning Sciences, 24(4), 504-549. https://doi.org/10.1080/10508406.2014.999270

Heyd-Metzuyanim, E., \& Graven, M. (2016). Between people-pleasing and mathematizing: South African learners' struggle for numeracy. Educationa Studies in Mathematics, 91(3), 349-373. https://doi.org/10.1007/s10649-015Studies

Hoch, M., \& Dreyfus, T. (2004, July). Structure sense in high school algebra: The effect of brackets. In M.J. Hoines \& A.B. Fuglestad (Eds.), Proceedings of the 28th Conference of the International Group for the Psychology of Mathematics Education (Vol. 3, pp. 49-56). Bergen: PME. Retieved from https://files.eric. ed.gov/fulltext/ED489561.pdf

Hoch, M., \& Dreyfus, T. (2006, July). Structure sense versus manipulation skills: An unexpected result. In J. Nonotná, H. Moraová, M. Krátká, \& N. Stehliková (Eds.), Proceedings of the 30th Conference of the International Group for the Psychology of Mathematics Education (Vol. 3, pp. 305-312). Prague: PME. Retrieved from of Mathematics Education (Vol. 3, pp. 305-3
https://files.eric.ed.gov/fulltext/ED496933.pdf

Linchevski, L., \& Livneh, D. (1999). Structure sense: The relationship between algebraic and numerical contexts. Education Studies in Mathematics, 40(2), 173-196. https://doi.org/10.1023/A:1003606308064

Mason, J., Stephens, M., \& Watson, A. (2009).Appreciating mathematical structure for all. Mathematics Education Research Journal, 21(2), 10-32. https://doi. org/10.1007/BF03217543

Maxwell, J.A. (1992). Understanding and validity in qualitative research. Harvard Educational Review, 62(3), 279-300. https://doi.org/10.4135/9781412986274

Morgan, C. (1998). Writing mathematically: The discourse of investigation. London: Falmer Press.

Nachlieli, T., \& Tabach, M. (2012). Growing mathematical objects in the classroom The case of function. International Journal of Educational Research, 51-52, 10-27. https://doi.org/10.1016/j.ijer.2011.12.007
Pournara, C., Hodgen, J., Sanders, Y., \& Adler, J. (2016). Learners' errors in secondary algebra: Insights form tracking a cohort from Grade 9 to Grade 11 on a diagnostic algebra: Insights form tracking a cohort from Grade 9 to Grade 11 on a diagnostic
algebra test. Pythagoras, 37(1), a334. https://doi.org/10.4102/pythagoras.v37i1. 334

Roberts, A. (2016). A study of Grade 8 and 9 learner thinking about linear equations, from a commognitive perspective. Unpublished master's thesis, University of Cape Town, Cape Town, South Africa. Retrieved from https://open.uct.ac.za/ Cape Town, Cape Th
handle/11427/20627

Seng, L. K. (2010). An error analysis of Form 2 (Grade 7) students in simplifying algebraic expressions: A descriptive study. Electronic Journal of Research in Educational Psychology, 8(1), 139-162. Retrieved from http://www.investigacionpsicopedagogica.org/revista/new/english/ContadorArticulo.php?382

Setati, M. (2003). "Re"-presenting qualitative data from multilingual mathematics classrooms. ZentralblattürDidaktik der Mathematik, 35(6), 294-300. https://doi. org/10.1007/BF02656693

Setati, M. (2008). Access to mathematics versus access to the language of power: The struggle in multilingual mathematics classrooms. South African Journal of Education, 28, 103-116.

Sfard, A. (2008). Thinking as communicating: Human development, the growth of discourses, and mathematizing. New York, NY: Cambridge University Press. https://doi.org/10.1017/CBO9780511499944

Sfard, A. (2015). Learning, commognition and mathematics. In D. Scott \& E. Hargreaves (Eds.), The Sage handbook of learning (pp. 129-138). London: Sage. https://doi. org/10.4135/9781473915213.n12

Sfard, A. (Ed.). (2012). Developing mathematical discourse: Some insights from communicational research. International Journal of Educational Research, 51-52, 1-9. https://doi.org/10.1016/j.ijer.2011.12.013

Sfard, A. (2017). Ritual for ritual, exploration for exploration: Or, what learners are offered is what you get from them in return. In J. Adler \& A. Sfard (Eds.), Research
for educational change: Transforming researchers' insights into improvement in for educational change: Transforming researchers' insights into improver
mathematics teaching and learning (pp. 41-63). Abingdon: Routledge.

Sinclair, N., \& Moss, J. (2012). The more it changes, the more it becomes the same: The development of the routine of shape identification in dynamic geometry environments. International Journal of Educational Research, 51-52, 28-44. https://doi.org/10.1016/j.ijer.2011.12.009

Skemp, R.R. (1976). Relational understanding and instrumental understanding. Mathematics Teaching, 77, 20-26.

Spaull, N. (2013). South Africa's education crisis: The quality of education in South Africa 1994-2011. Johannesburg: Centre for Development \& Enterprise. Retrieved from http://www.section27.org.za/wp-content/uploads/2013/10/Spaull-2013CDE-report-South-Africas-Education-Crisis.pdf

Tabach, M., \& Nachlieli, T. (2011). Combining theories to analyse classroom discourse: A method to study learning process. In M. Pytlak, T. Rowland, \& E. Swoboda (Eds.) Proceedings of the Seventh Congress of the European Society for Research in Mathematics Education (pp. 2524-2538). Rzeszów, Poland: University of Rzeszów.

Tabach, M., \& Nachlieli, T. (Eds.). (2016). Communicational perspectives on learning and teaching mathematics: Prologue. Educational Studies in Mathematics, 91(3) 299-306. https://doi-org.ez.sun.ac.za/10.1007/s10649-015-9638-7

Taylor, N. (2009). The state of South African schools. Part 1: Time and the regulation of consciousness. Journal of Education, 46, 9-32. Retrieved from http://joe.ukzn. ac.za/Libraries/No_46_June_2009/Completeissue_No_46.sflb.ashx\#page=13

Venkat, H. \& Adler, J. (2012). Coherence and connections in teachers' mathematical discourses in instruction. Pythagoras, 33(3), Art\#188, 1-8. http://dx.doi org/10.4102/pythagoras.v33i3.188

Viirman, O. (2011). Discourses of functions: University mathematics teaching through a commognitive lens. In M. Pytlak, T. Rowland, \& E. Swoboda (Eds.), Proceedings of the Seventh Congress of the European Society for Research in Mathematics Education (pp. 2103-2112). Rzeszów, Poland: University of Rzeszów. 